\title{
Effect of Curriculum Change on TIMSS Achievement in Bahrain
}

\author{
Masooma Al Mutawah ${ }^{1}$, Ruby Thomas ${ }^{1}$, Yazan Alghazo ${ }^{1} \&$ Maha Al Anezi ${ }^{2}$ \\ ${ }^{1}$ Bahrain Teachers College, University of Bahrain, Kingdom of Bahrain \\ ${ }^{2}$ Ministry of Education, Kingdom of Bahrain \\ Correspondence: Masooma Al Mutawah, Bahrain Teachers College, University of Bahrain, Kingdom of Bahrain. \\ E-mail:malmutawah@uob.edu.bh
}

Received: April 22, 2020

doi:10.5539/ies.v13n10p35
Accepted: June 6, 2020 Online Published: September 21, 2020

URL: https://doi.org/10.5539/ies.v13n10p35

\begin{abstract}
The Trends in International Mathematics and Science Study (TIMSS) is one of the most influential assessments of student achievement conducted at regular interval every four years. It provides reliable data about the mathematics and science achievement of students in grade 4 and grade 8 , as well as data that informs instruction, curriculum development and teaching-learning process. Curriculum related factors are among the most prominent elements that affect TIMSS results. This study explores the impact of recent revisions in the school mathematics curriculum implemented by the Ministry of Education in Bahrain (The Bahrain Numeracy Strategy) on the TIMSS achievement results. The analysis focuses on the three cognitive domains (Knowing, Applying \& Reasoning) as well as the three content domains (Number, Geometric Shapes and Measurement \& Data Analysis) among fourth grade students. A thorough review of the curriculum and structured interviews and reflections with in-service teachers who witnessed a prominent change in the outcome revealed that Bahraini students' scores improved in all three content domains while comparing 2011 and 2015. The possible explanations and reasons for those changes in achievement are further discussed.
\end{abstract}

Keywords: achievement; Bahrain numeracy strategy, cognitive domain, content domain

\section{Introduction}

The 21 st century requires all students to use higher order skills in their daily lives. Bahrain is a part of a universal 21 st century view where the 2030 vision of Bahrain is to improve education for a better human capital. There have been modifications in the mathematics curriculum in Bahrain to improve the mathematical performance of all students. In 2013 the ministry of education implemented the numeracy strategy in primary schools; two years after, grade 7 was included as well (Al-Awadhi, 2015). Additionally, the Ministry of Education (MOE) in Bahrain implemented several different projects to improve education; one of the projects was to increase the lesson period for math and science from 45 minutes to 1 hour (Al-Awadhi, 2015). 'King Hamad Schools of Future' is a project that aims at using technology in teaching and learning to improve the community of Bahrain (Sector Report GCC Education, 2016). As a concern about the quality of education, Bahrain established the National Authority for Qualifications and Quality Assurance of Education and Training (QQA) with the purpose of supporting the Bahrain institutions to adhere to global standards in education ("Sector Report GCC Education," 2016). The QQA conducts National examinations to determine the performance of the students in the four core subject areas: English, Arabic, Mathematics and Science. The National tests are designed by trained Bahraini teachers that are certified by Cambridge International Examinations (CIE) and those exams are implemented for Grades 3, 6, 9 and 12 (Bahrain Education and Training [BQA], 2017).

The Kingdom of Bahrain participated in the Trend in International Mathematics Studies (TIMSS) in 2003 with only Grade 8 students and in 2007 as well. But in 2011 and 2015 Grade 4 and 8 participated in TIMSS. TIMSS is a global examination to evaluate the students' abilities in mathematics and science every four years. Another tool that is used to evaluate the country's performance is a nation-wide questionnaire for teachers, students, principals and parents (BQA, 2017). The TIMSS consists of four scale benchmark, the Advanced Benchmark with 625 scale points, in this scale the students solve complex problems with providing reasons and explanations of their solutions. In 550 scale points this is the High Benchmark, in this scale students use knowledge to solve problems. The third scale is the Intermediate Benchmark with 475 scale points, in this scale students solve simple problems using their knowledge. The fourth scale is Low Benchmark with 400 scale points, in this scale students have some 
basic knowledge of mathematics (Mullis, Martin, Hooper, \& Foy, 2016).

In 2011, Bahrain's average performance in TIMSS for Grade 4 in math was 436 scale points and for Grade 8 in math it was 409 scale points. The result has improved in 2015 were Grade 4 in math got 451 scale point with a difference of 15 scale points and Grade 4 in math got 454 with a difference 45 scale points. Bahrain is still under TIMSS scale CenterPoint which is 500 (Mullis, Martin, Hooper, \& Foy, 2016).

\section{Literature Review}

TIMSS is an international scale assessment that more than 60 countries participate in (BQA, 2017). Bahrain has participated since 200. Bahrain had been scoring below the CenterPoint of 500. Therefore, it is recognized that Bahrain must take the needed steps to improve these results. According to Rutkowski, Gonzalez, Joncas, and Davier (2010) "TIMSS, PIRLS, and PISA feature a wealth of contextual background information from participating students and their homes, teachers, and schools. Student background questionnaires solicit information regarding attitudes toward learning, home environment, study and leisure habits, and perceptions of school climate, among a host of other student background domains" (p. 142). All this is reflected in the TIMSS result and that reflect the quality of education in the country. Moreover, according to Ritzen (2013) "The main point is that assessments make comparisons in the accomplishments of different institutions or regions possible. They can take the role of signaling the quality of the educational institutions or the educational establishment of a region or a country. This signal can drive a healthy competition in which all participating partners' profit" (p. 14).

The U.S. Department of Education stated "TIMSS also provides new information about why our students perform as they do. To understand the curriculum as it is intended to be taught, TIMSS researchers studied curricular frameworks, textbooks, and other materials of participating nations and surveyed their educational authorities" (p. 6). In order for the educator and policy maker to help the students reach CenterPoint for better qualified worker with the knowledge of mathematics. Furthermore, according to Rutkowski and Prusinski (2011) "inform national and local policy about schools' curricula and instruction" (p. 3). This will help improve Bahrain's reputation internationally to be known for the educational quality within its public schools.

In Slovenia TIMSS result in 1995 which was 462 points and that make the Slovenia change the way that mathematics is taught (Grønmo, Pavešić, Nyström, \& Onstad, 2013). One challenge is that the content of mathematic was not taught on their prior knowledge (Grønmo et al., 2013). Also, the university teachers' emphasis on the importance of not teaching the earlier students advance mathematic such as: integer where misconception can increase in this age (Grønmo et al., 2013). Slovenia removed, the theory of number set for third grade where the content demands abstract knowledge (Grønmo et al., 2013). In addition, the advance algebra with equation was removed from fourth grade students (Grønmo et al., 2013). After 15 years, this type of program helped raise students' achievement significantly (Grønmo et al., 2013).

Another challenge is that the data representation was not taught in elementary grades and it was not important in college, so the teachers were concerned regarding having enough content knowledge to teach this such topics. In 1995, the results of TIMSS show that students had an average level of data representation and, therefore, the area of data representation was recognized as an essential part of the curriculum and more emphasis was placed on teaching this topic (Grønmo et al., 2013).

In Singapore, in the seventies there was a problem with using language in the curriculum and they use vernacular languages for instruction and English for all levels. The language has become a problem that they face while planning the curriculum (Gopinathan, 2002). Also, there is an issue with the different abilities of the students and that develop three courses in secondary; Special/Express, Normal (Academic) and Normal (Technical) (Lessani, Yunus, Tarmiz, \& Mahmud, 2014). In 1997, it was the start of developing creativity in schools (Gopinathan, 2002).

In China 1996 there was a beginning to reform the curriculum and the country conducted a survey to change the curriculum (Wang, Bian, Xin, Kher, Houang, \& Schmidt, 2012). In the survey, there were different challenges that the school staff faced. One was that there were a lot of topics to cover and another is that some topics are difficult that did not suit the students' development (Wang et al., 2012). Also, the shortage in time for teaching the lessons. In 1998, the researcher work on the curriculum reform and in 1999 there was a requirement to change the curriculum. In 2000 there was the draft for reform and in 2005 all the students start to learn using the new curriculum (Wang et al., 2012).

In 1994 Swedish there was a curriculum reform (Grønmo et al., 2013). The students whom participate in TIMSS 2007 and TIMSS 2011 they was from the curriculum reformed 1994. The result in 2007 was 503 and in 2011 it was 504 points (Grønmo et al., 2013). In 2011 Swedish implement a new curriculum and 2015 was the TIMSS participated from curricula 2011 reformed and the result was 519 points (Mullis, Martin, Hooper, \& Foy, 2016). 
In 1990 there was a reform in the curriculum in U.S (Woodward, 2004). In 2015, grade four results increased in achievement to 539 points and the result was higher than 1995, 2003 and 2007 result. Also, grade eight achieved 518 in 2015 TIMSS result (Provasnik, Malley, Stephens, Landeros, Perkins, \&Tang, 2016).

In Slovenia, the curriculum changed after 1995 TIMSS result where it was 462. The result in 2003 showed an improvement with 479 points. In 2007, Slovenia achieved 502 points than 513 points in 2011(Grønmo et al., 2013). In 2015, Slovenia reaches 520 points (Mullis et al., 2016).

In Bahrain, the numeracy strategy started in 2013 and the result of TIMSS in 2011 was 436 points (Al-Awadhi, 2016). In 2015, after the numeracy strategy the result raises to reach 451 points (Mullis et al., 2016).

There are many factors related to curriculum that affect TIMSS results. First, teacher education-the teacher is the facilitator for the learning in class. According to Dodeen (2012) "Some teachers' qualifications and practices were found to be related to students' scores" (p.61). Also, professional development-the school staff know who to use the resources to implement the curriculum. As Mizell (2010) stated "As all educators on the team become more skillful, they reduce or eliminate variations in performance and begin to take collective responsibility for the success of all students, rather than just their own" (p.11). However, these factors are not addressed in this study as possible contributors to student achievement, and emphasis is placed on how curriculum change can affect student performance.

Curriculum is the usual term to express any activity to plan and implement an educational training. The curriculum is situated between the declaration of general principles and their practical translation, between what has been prescribed and what really happens in the classroom (Stenhouse,1984). According to NCTM(2000), curriculum development or reforms encourage teaching practices that are different from the current ways. Traditionally, curriculum change models in education have been activities-centered (Smeed,2009). Such models concentrate on activity, rather than results or impact, promoting changes that were externally facilitated, tightly focused results driven and timely on implementation. According to Tanner and Tanner (2007), "The school curriculum is presumably designed not only to inculcate each member of the rising generation in the best elements of knowledge, but also to enable each one to use that knowledge to improve the life of the individual and the life of society". (p. 121)

A review of literature recommends that curriculum itself is not the only factor of success in student learning (Senk \& Thompson, 2003; Stein et al., 2007). It is evident that teachers make use of curriculum materials in a range of diverse ways in their classrooms (Kilpatrick, 2003; Reys, Tarr, \& Chávez, 2004; Stein \& Kaufman, 2010). In a longitudinal study that involved classroom observations, Cai, Wang, Moyer, Wang, and Nie (2011) examined the special effects of different curricula as well as instruction on the learning of algebra in middle school classes. The results from this study showed that greater growth in problem-solving skills for students using the special curriculum than those using the other curricula.

Moreover, Mizell (2010, p. 19) emphasis on continuing development of teacher "When educators learn, students learn more." Another factor is the use of technology in the classes. According to IEA (2015) "Students who regularly use a computer or tablet at home generally achieve better results in mathematics and science than students who don't". This is a reason for involving technology in teaching to help the students raise their achievement. As Chaudhary (2015) stated that "no meaningful teaching and learning take place without adequate resource materials" (p. 985). Also, the learner is the key for implementing curriculum where the learner experience and ability affect the teaching of curriculum (Chaudhary, 2015).

In a study conducted by Kim et al. (2013) to examine the effect of students' educational context in the TIMSS result, found that there are factors that predict the students and school level. In this study there was a comparison between Korea, Singapore, and Finland. They found that the increases study material at home help both Korea and Singapore to achieve higher in mathematic for both grades 4 and 8 . However, in Finland the positive affect for only grade 4 students. Also, in this study there was an increase in the achievement because of valuing math and the students' confidence in math in both Korea and Singapore.

\section{Methodology}

This study utilized descriptive statistics to analyze the TIMSS results for Bahraini fourth grade students obtained in 2015; the results from 2015 were compared to the results obtained in 2011 to investigate the trend in Mathematics achievement among Bahraini fourth graders. More specifically, the analysis focused on differences in achievement between the 2011 and 2015 results in the three main cognitive domains (Knowing, Applying, Reasoning) and the three main content domains (Numbers, Geometric shapes and measurement, Data Display).

To explore any connections between the curriculum review conducted by the Ministry of Education after the 
results of 2011 and any differences in achievement obtained in the 2015 results, the authors conducted a thorough review of the curriculum changes using the textbooks used before and after the implementation of the curriculum change as well as the associated national standards. Also, semi-structured interviews were conducted with in-service teachers to gauge their perspectives on the main highlights of the curriculum review. The sample of seven $(n=7)$ teachers was purposively selected from five different Bahraini public schools; the reason for the purposive sampling was to select teachers who had been employed and working during the curriculum review and are able to reflect on the main changes in the curriculum.

\section{Results and Discussion}

The TIMSS examinations measure students' abilities in Mathematics in three different content domains: a) Number, b) Geometric shapes and Measurements, and c) Data Display; the analysis revealed that Bahraini students' scores improved in all three content domains. Table 1 shows the scores of Bahraini fourth grade students in 2011 and 2015 on all three content domains.

Table 1 shows that Bahraini students improved in their scores on all three content domains; in 2011, they scored a total of 439 , while in 2015 , their scores increased 14 points to 453 on the Number domain. Similarly, students' scores increased in the "Geometric Shapes and Measurements" domain from 422 in 2011 to 447 in 2015, which reflects a 25-point increase. Finally, on the Data display domain, students' scores increased from 442 in 2011 to 454 in 2015 with a 12-point increase.

Table 1. Bahraini fourth grade students results per content domain in 2011 and 2015

\begin{tabular}{ccc}
\hline Domain & TIMSS Score (2011) & TIMSS Score (2015) \\
\hline Total Score & 436 & 451 \\
Number & 439 & 453 \\
Geometric Shapes and Measurement & 422 & 447 \\
Data Display & 442 & 454 \\
\hline
\end{tabular}

Within each of the content domains, students' achievement was measured in three different cognitive domains (Knowing, Applying, and Reasoning). An analysis of the Bahraini fourth grade students revealed increased scores on all three cognitive domains overall and within the content domains. The overall score for the knowing domain increased from 438 in 2011 to 453 in 2015, which reflects a 15-point increase. Scores on the "applying" domain also increased from 431 in 2011 to 450 in 2015, which reflects a 19-point increase. Also, the overall score for the "Reasoning" domain increased from 439 in 2011 to 447 in 2015 with an 8-point increase. Table 2 shows Bahraini fourth grade students' scores on the three cognitive domains in both 2011 and 2015 TIMSS results.

Table 2. Bahraini fourth grade students results per cognitive domain in 2011 and 2015

\begin{tabular}{ccc}
\hline Domain & TIMSS Score (2011) & TIMSS Score (2015) \\
\hline Knowing & 438 & 453 \\
Applying & 431 & 450 \\
Reasoning & 439 & 447 \\
\hline
\end{tabular}

Bahraini fourth grade students demonstrated improvement in the specific cognitive domains within each content domain. Table 3 shows students' grades in each cognitive domain within each content domain. 
Table 3. Bahraini fourth grade students results for specific cognitive domains within each content domain in 2011 and 2015

\begin{tabular}{cccc}
\hline Content Domain & Cognitive Domain & $\begin{array}{c}2011 \\
\text { Compared to Average }\end{array}$ & $\begin{array}{c}2015 \\
\text { Compared to Average }\end{array}$ \\
\hline \multirow{3}{*}{ Number } & Knowing & $40 \%$ & $82 \%$ \\
& Applying & $48 \%$ & $70 \%$ \\
& Reasoning & $40 \%$ & $85 \%$ \\
\hline \multirow{3}{*}{ Geometric shapes and measurement } & Knowing & $40 \%$ & $119 \%$ \\
& Applying & $79 \%$ & $80 \%$ \\
& Reasoning & N/A & $72 \%$ \\
\hline \multirow{2}{*}{ Data Display } & Knowing & N/A & $100 \%$ \\
& Applying & $102 \%$ & $94 \%$ (High) \\
& Reasoning & $72 \%$ & $52 \%$ (Advanced) \\
\hline
\end{tabular}

The curriculum review and the thematic analysis of the interviews revealed that certain changes to the curriculum could have contributed greatly to the improvement of Bahraini Fourth grade students' scores on the TIMSS examinations. The curriculum review that was conducted in 2011 by the Ministry of Education (MOE) in Bahrain included a wide range of changes to the textbooks and the teaching resources provided to teachers. One of the participants answered the question with "increases in the content and diversity of the subject by adding probability, statistics, geometry and algebra". Other participants have added that there are different methods to solve a mathematic problem. Also, adding mental lessons to improve the students' mathematic skills and that the topics are suitable to the students age. A participant had stated "after the change in the curriculum there are training for teacher to apply mathematic skill and invest in the teaching aids to help in math teaching and learning process".

In addition, the teachers added that there are higher order mathematic problems and that there were increases in the differentiation of mathematical problems. Furthermore, most of the teachers agree the lesson plans that were provided had helped the teachers in the lesson and provide a clear direction to follow in the class with the focus on the basic mathematic skills. Nevertheless, another improvement that the participants agrees on is that the teaching aids that was provided helped the teacher to explain the mathematic content because they had a training on how to teach the new topics such as: mental mathematic lesson and skills. A participant said that "the new curriculum help the teacher to know exactly what is important to teach and organize the lesson".

Moreover, the introduction of Bahrain Numeracy Strategy into the Bahraini school system might have contributed to this impressive increase in student performance on the TIMSS. In September of 2012, the Bahrain Numeracy Strategy (BNS) was launched and introduced into the mathematics curriculum in Bahrain. The strategy mainly aimed at increasing numeracy standards and raising student performance in Mathematics. The BNS utilizes a structured approach in improving teaching and learning, assessment and curriculum planning in Bahraini schools.

According to the published introduction guide, these goals can be achieved through: (Introduction Guide, Bahrain Numeracy Strategy, 2012)

- Providing a framework and guidance that exemplifies the mathematics that should be taught in each grade.

- Providing a framework, guidance, training and support for principals and teachers on how mathematics should be taught and assessed.

- Involving everyone in the system to ensure a consistent approach to teaching and learning mathematics in Bahrain.

Moreover, a deeper examination of the BNS strategy with regards to specific content domains revealed that it provides significant support and enhancement to the understanding and allows students to reach mastery levels within each of the content domains; it serves as a strong supporting tool for the reformed textbooks.

For example, within the Geometry and measurements domain, an examination of a lesson on types of angles revealed that it adds more rigor examples and helps students create their own knowledge. The lesson contains many varied exercises for students. Students will learn the characteristics of 4 different angles and use this information to identify and draw the angles.

Another lesson that falls under the Number domain, more specifically pattern identification showed that in BNS Students are required to generate number patterns, describe and record the missing numbers in the patterns. The teaching strategies focus on the thinking process, using 100 chart, tables of addition and multiplication, number 
line, skip counting. In another lesson that falls within the number domain (Introduction to Fractions), the analysis revealed that prior to the introduction of BNS, this lesson would begin with a definition of a fraction and one example of a fraction that represents $1 / 8$. The lesson also included several problems and examples on different fractions. Finally, it was noted that the lesson also began with the introduction of five new vocabulary terms believed to be necessary for students' comprehension of the concept of fractions; those vocabulary terms included Fraction, denominator, nominator, equivalent fractions, and fractional numbers.

On the other hand, the addition of BNS expanded this lesson by adding more vocabulary to the list of terms teachers are encouraged to introduce and review with students; this list included terms such as, Whole, part, unequal, equal, fraction, numerator, denominator, proper, improper, mixed number, half, quarter, third, fifth, sixth, seventh, eighth, ninth, tenth, eleventh, twelfth, equivalent, reduced to, cancel, lowest terms, simplest form, simplify, unit fraction, reciprocal. Moreover, the newly introduced lessons included an extensively higher number of visual representations of fractions, which allow students to reach higher levels of understanding and comprehension of the concept of a fraction.

The methods of instruction were also much more varied in BNR that they had been in the originally used textbook, for example, the original textbook mainly used a paper folding activity and included questions that asked students to WRITE the answer or DRAW the fraction that represented the fraction. While in BNR the teacher would use manipulatives, such as blocks to help students represent fractions, shading is also used in the examples, along with high-level real world problems that require an understanding of fractions.

\begin{tabular}{|c|c|}
\hline \multicolumn{2}{|c|}{$\begin{array}{l}\text { Fractions as parts of a whole } \\
\text { Lesson Idea: Understand regular fractions, write fractions, and read fractions. }\end{array}$} \\
\hline \multicolumn{2}{|c|}{$\begin{array}{l}\text { Prepare: A piece of pie includes two types of slices, some slices include meat and cheese and other include only } \\
\text { cheese. } \\
\text { Those pieces of pies can be described using fractions. } \\
\text { - A fraction could represent a part of a whole, or a part of a group; in a fraction the numerator indicates the number } \\
\text { of matching pieces of a whole, and the denominator denotes the whole number of pieces. }\end{array}$} \\
\hline \multicolumn{2}{|c|}{$\begin{array}{l}\text { Real life Example: Fraction representation: } \\
\text { Farming: A group of school students plant a garden as part of their science class; they need to plant } 1 / 3 \text { of the garden } \\
\text { with vegetables. }\end{array}$} \\
\hline First method: using rectangle & Second method: using circle \\
\hline $\begin{array}{l}\text { Dived the rectangle into three } \\
\text { equal parts, shade one part that } \\
\text { represent one third. }\end{array}$ & $\begin{array}{l}\text { Dived the circle into three equal } \\
\text { parts, shade one part that } \\
\text { represent one third. }\end{array}$ \\
\hline
\end{tabular}

Figure 1. Number domain example from the original textbook 


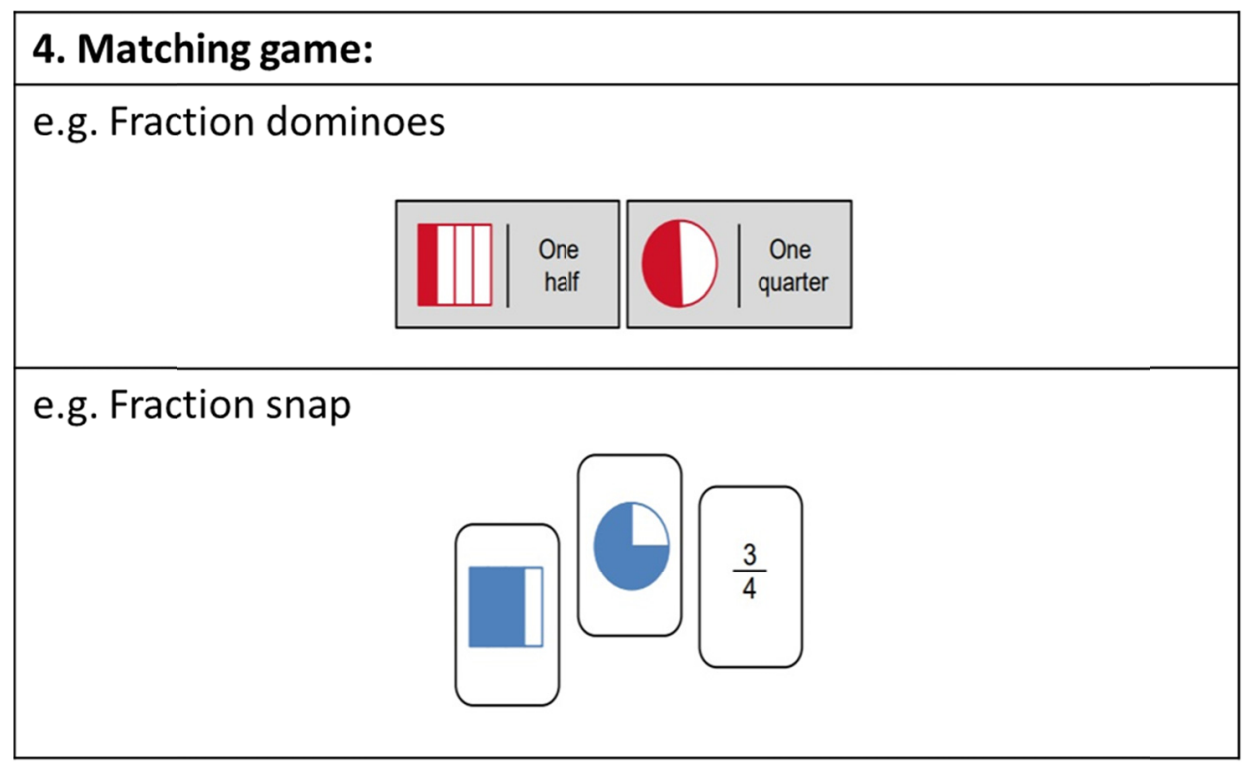

Figure 2. Number domain example from Bahrain numeracy strategy

Another example of notable changes appeared in the analysis of geometry-related materials. In the original textbooks, the topic of "triangles" was introduced by simply providing definitions of the different types of triangles, then providing students with examples of questions asking them to classify triangles. In BNR material, however, the lessons begin with addressing the most common misconceptions and errors students face when learning about triangles, moreover, the teaching strategies in the lesson are diversified enough to allow for more learning opportunities through group activities, peer activities, and individual activities, which is very apparent in the accompanied detailed lesson plan.

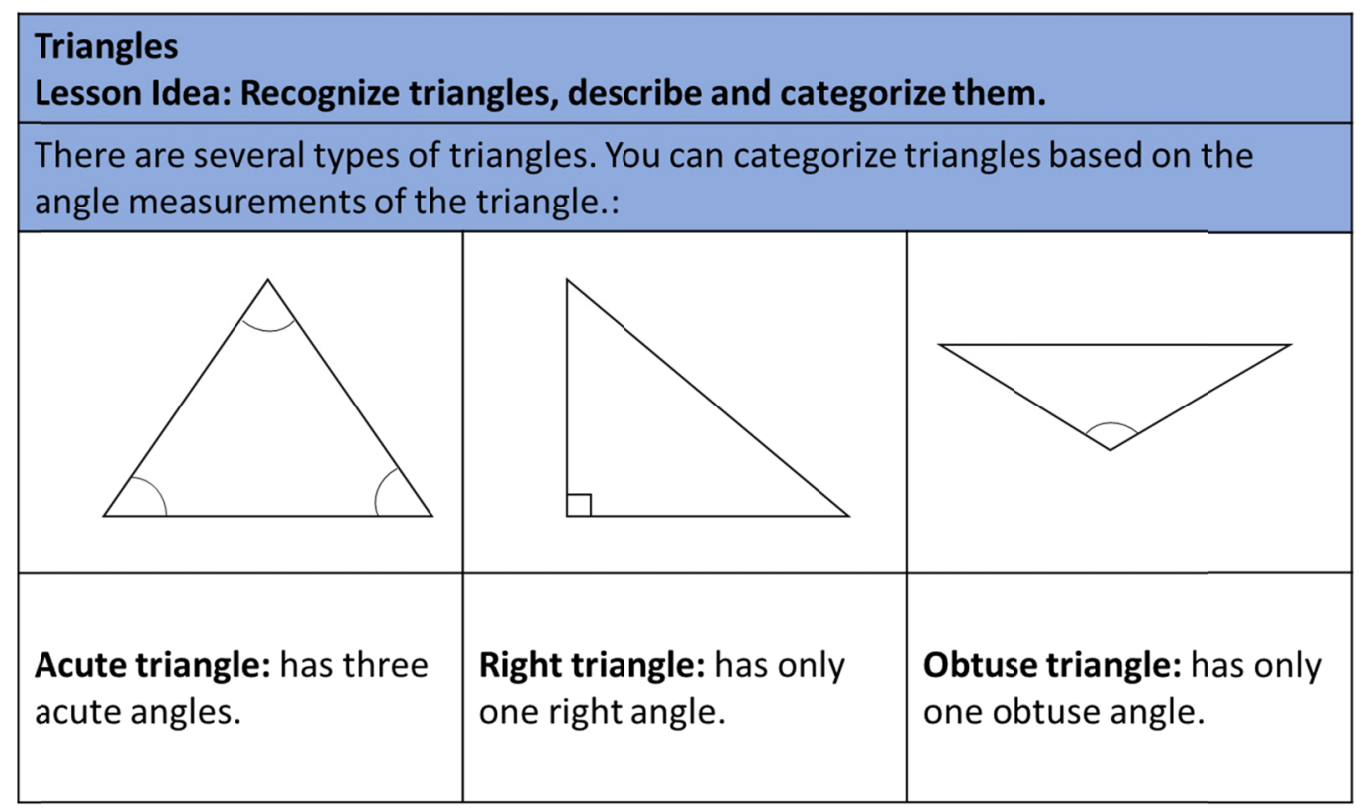

Figure 3. Geometry domain example from the original textbook 


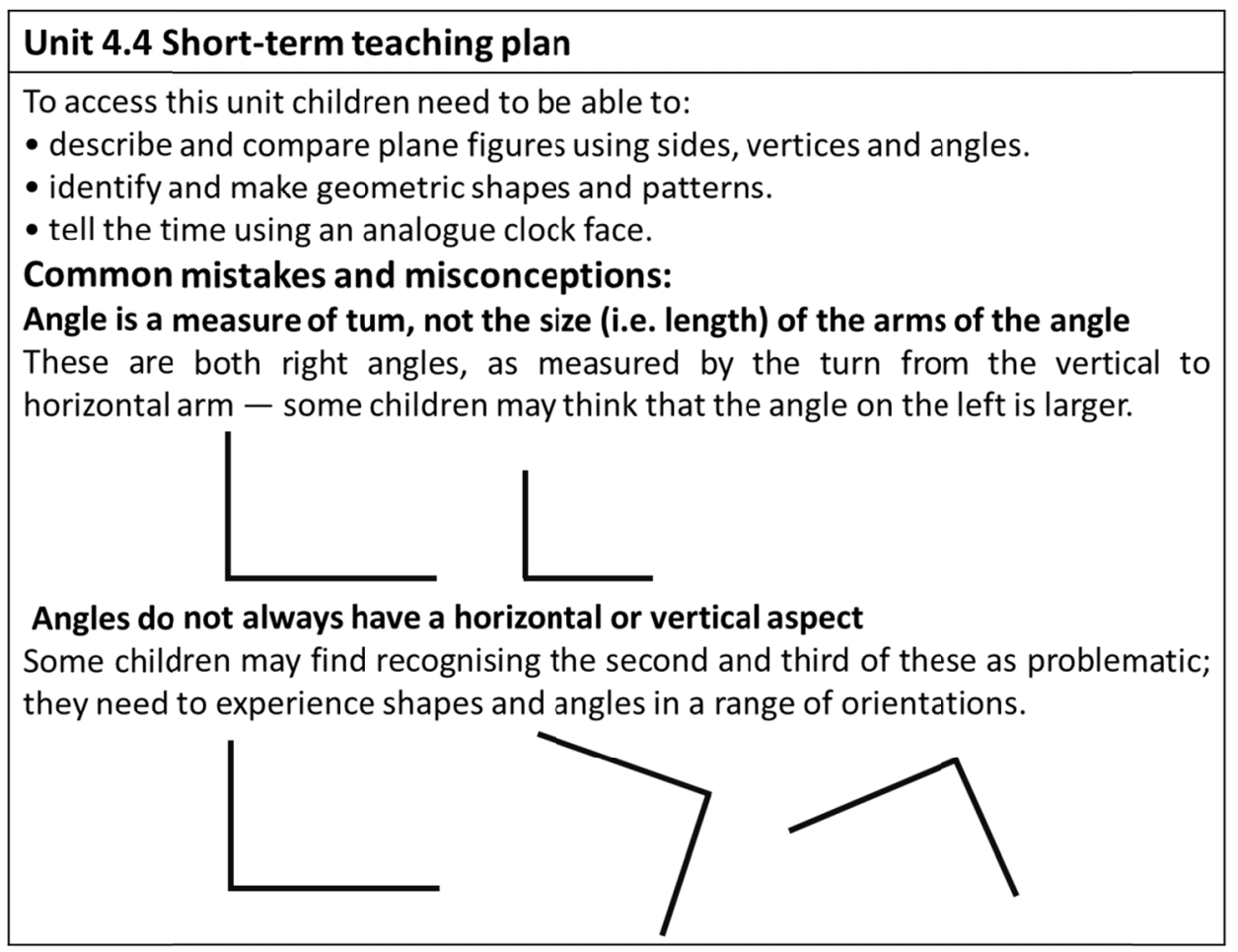

Figure 4. Geometry domain example from Bahrain numeracy strategy

In addition, the same additional differentiation of instructional strategies as well as higher order problems appears about reading data from tables, which falls under the Data Analysis domain; the most common way to display and demonstrate different sets of data and information is through tables and charts. The students are taught to read information from a picture, graph, table or diagram as well as Construct displays without the use of digital technologies using multiple methods of representation and instruction that are suitable for different levels of students as well as different learning styles. This provides an opportunity to discuss how and why information can be interpreted, which in turn enhances the research skills for all students. 
Data collection and organization

Lesson Idea: Data collection and organization.

The teacher asked the students about their hobbies, and the results were as follows:

\begin{tabular}{|l|l|l|}
\hline \multicolumn{1}{|c|}{ Reading } & \multicolumn{1}{c|}{ Drawing } & \multicolumn{1}{c|}{ Arabic Calligraphy } \\
\hline Fatimah & Suad & Nujood \\
\hline Maha & Amal & Salma \\
\hline Zainab & Aysha & Maryam \\
\hline Alanood & Layla & \\
\hline Lubna & \multicolumn{2}{|c|}{} \\
\hline
\end{tabular}

What the teacher did is called a survey, which is a method of collecting Data or information that answers a certain question. Data can be organized into a Tally chart or a Frequency table. Real life example: Data organization

Hobbies: Look at the data collected by the teacher and organize it into:

1) Tally chart

2) Frequency Table.

\section{Organize the information in a frequency table and tally table:}

Step one: Create a two columns table and write a title for it.

Step two: write each hobby in the first column.

Step three: use tallies or numbers to record the results

Frequency table

\begin{tabular}{|c|c|}
\hline \multicolumn{2}{|c|}{ Students' Hobbies } \\
\hline Hobby & Frequency \\
\hline Reading & 5 \\
\hline Drawing & 4 \\
\hline $\begin{array}{c}\text { Arabic } \\
\text { Calligraphy }\end{array}$ & 3 \\
\hline
\end{tabular}

Tally table

\begin{tabular}{|c|c|}
\hline \multicolumn{2}{|c|}{ Students' Hobbies } \\
\hline Hobby & Tally \\
\hline Reading & H† \\
\hline Drawing & ||| \\
\hline $\begin{array}{c}\text { Arabic } \\
\text { Calligraphy }\end{array}$ & \|\| \\
\hline
\end{tabular}

Figure 5. Data analysis example from the original textbook

\section{Main activity}

Revise tally charts and consider questions that arise from the information.

Show the children a tally chart like the one below

\begin{tabular}{|c|c|c|}
\hline colour & Tally & Frequency \\
\hline Sliver & HH HYT & \\
\hline Black & HTI & \\
\hline White & H HWHYHTII & \\
\hline Red & III & \\
\hline
\end{tabular}

What is this type of chart called? What is a tally? Make sure all the children that the tally is a count of the number of the times that something happened. How many each colour happened? What is the frequency for each colour?

Remind the children that each group of five has four vertical tally marks and the fifth tally mark cuts across them. Emphasise that when tallying, counting in fives is quicker.

Figure 6. Data analysis example from Bahrain numeracy strategy 
Another notable example is the topic of probability; in the textbook, the topic is addressed only in one lesson that includes three examples and only a description of what probability is. While in the Bahrain Numeracy Strategy, the topic is extensively addressed through several activities and lessons in order to ensure comprehension and conceptualization of the topic. Figures 7 and 8 show the difference in both.

\begin{tabular}{l} 
Probabilities \\
Real life example: Using words to describe probability \\
\hline $\begin{array}{l}\text { Money: The table shows the different money bills in Rashed's wallet. Let us assume that he } \\
\text { lost one bill. Describe the probability that he lost a } 10 \text { BD bill. }\end{array}$ \\
Solution: There are five 10BD bills out of a total of 8 bills. Therefore, the probability that the \\
lost bill is a 10BD bill is the highest probability. \\
$\qquad$\begin{tabular}{|l|c|}
\hline \multicolumn{1}{|c|}{ Bill category } & Frequency \\
\hline 20 Dinars & 2 \\
\hline 10 Dinars & 5 \\
\hline 1 Dinar & 2 \\
\hline Total & 8 \\
\hline
\end{tabular} \\
Example: Using numbers to describe probability \\
The letters of the words (Math Notebook) were each written on a index card. Use numbers \\
(frequencies) to describe the possibility of randomly selecting one of the letters (M, T, O), \\
without looking at the cards. \\
Since there are six cards with the letters (M, T, O) out of a total of 12 cards. Then, the \\
possibility of drawing a card with one of the letters (M, T, O) written on it is six out of twelve.
\end{tabular}

Figure 7. Probability example from the original textbook

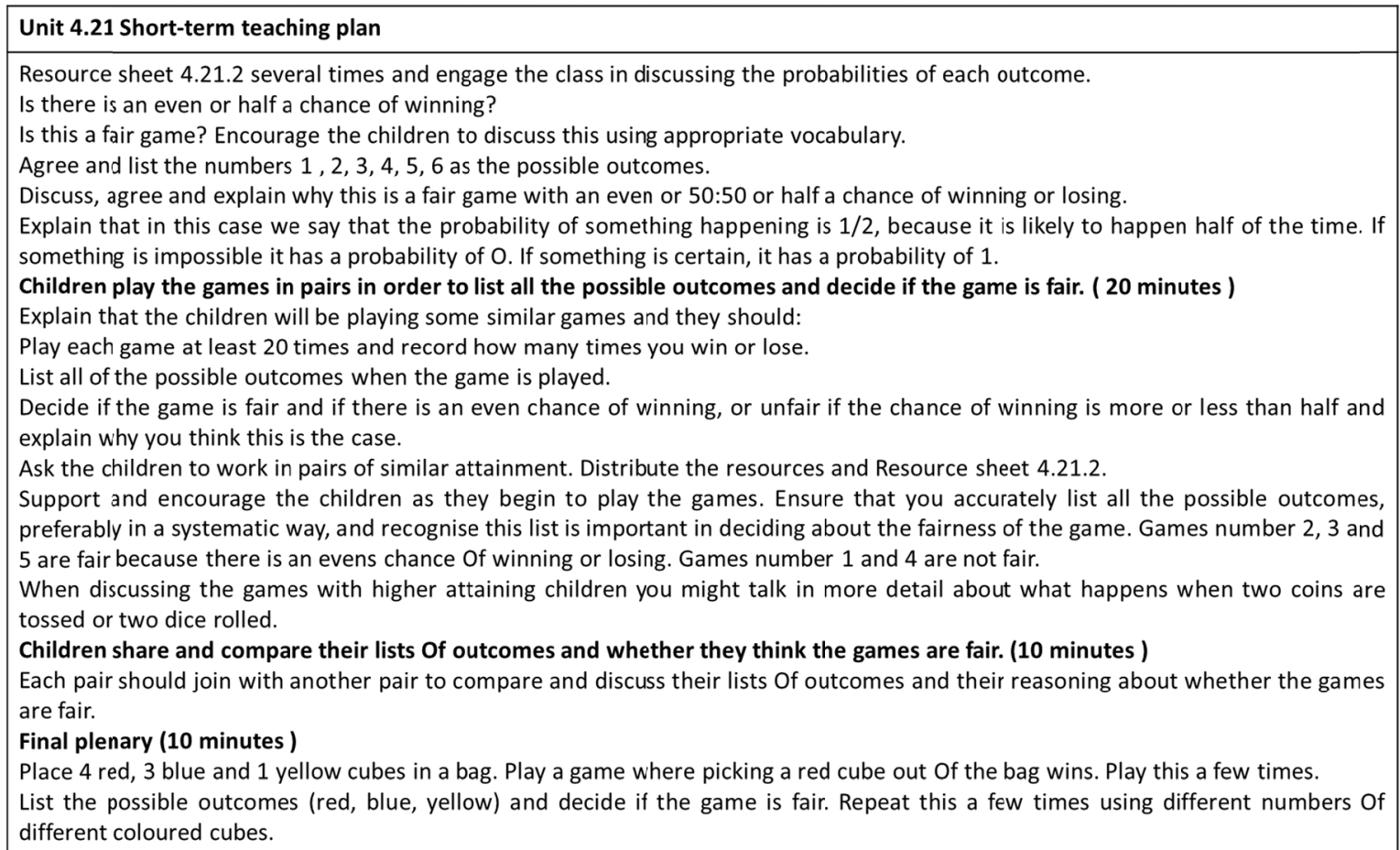

Figure 8. Probability example from the Bahrain numeracy strategy

This conclusion regarding the positive affect of the introduction of the Bahrain Numeracy strategy was further emphasized by all seven teachers who were interviewed; they emphasized that they believed the most significant 
changes to the curriculum that could have influenced student results are the mental math activities and additional resources offered through the Bahrain Numeracy Strategy. This calls for further analysis of the specific gains and benefits of such strategies.

\section{Conclusion}

In conclusion, this study aimed at exploring the differences in achievement among Bahraini Fourth grade students on the TIMSS examinations between the years 2011 and 2015. Moreover, the researchers attempted to explain any possible reasons for any differences in those results. To achieve these goals, a detailed analysis of the TIMSS results for both 2011 and 2015 was conducted, along with interviews with teachers from 5 different public schools in Bahrain.

The results showed that students' scores on TIMSS had improved on all cognitive and content domains between the years 2011 and 2015. The overall TIMSS math scores for fourth graders in Bahrain increased from 436 in 2011 to 451 in 2015.

Furthermore, results from textbook analysis, as well as interviews with in-service teachers revealed that significant improvements were made to the Bahraini curriculum after the 2011 TIMSS and included the introduction of the Bahrain Numeracy Strategy (BNS), as well as the addition of several lessons, topics, and a plethora of teaching resources based on best practice research. The BNS curriculum helped teachers to take into account the students' academic abilities in their classrooms and create a curricular path to reach students' full potential, which goes beyond a focus on rote memorization and test preparation. These meaningful learning experiences allowed making connections between the school and the real world.

Even though there are various parameters that affect students' achievement, curriculum and instructional practices tend to have a greater influence on student performance than state regulations and policies (Wang et al., 1993). The customized BNS curriculum at the local level positively influenced student's mathematics achievement and helped students reach their full potential. The curriculum is well structured to allow students the opportunity to engage in meaningful learning experiences with an emphasis on problem-solving in various real-life contexts.

The study concludes that these changes to the curriculum could have significantly contributed to the improvement of students' scores in all three cognitive domains, as well as the improvements in all three content domains. Further analysis of the specific gains and benefits of the curriculum review after 2011 and Bahrain Numeracy Strategy are strongly recommended for further study and an understanding of the impact these results will have on future curriculum development. This research has a potential to expand to study the influence of the curriculum development on other grade levels as well as the national examinations. We can expand this study to other grade levels and compare with the outcome of the national examination and other MOE examinations. We can also compare the curriculum with that followed by the private schools in Bahrain.

\section{References}

Al-Awadhi, H. (2016). Bahrain. In I. Mullis, M. Martin, S. Goh, \& K. Cotter (Eds.), TIMSS 2015 Encyclopedia: Education Policy and Curriculum in Mathematics and Science. TIMSS \& PIRLS International Study Center, Boston College.

Bahrain Education and Training. (2017). Bahrain Education Training Annual Report 2017. Bahrain.

Cai, J., Wang, N., Moyer, J. C., Wang, C., \& Nie, B. (2011). Longitudinal investigation of the curriculum effect: An analysis of student learning outcomes from the LieCal Project. International Journal of Educational Research, 50(2), 117-136. https://doi.org/10.1016/j.ijer.2011.06.006

Chaudhary, K. (2015). Factors affecting curriculum implementation for students. International Journal of Applied Research, 1(12), 984-986.

Dodeen, H., Abdelfattah, F., Shumrani, S., \& Abu Hilal, M. (2012). The Effects of Teachers' Qualifications, Practices, and Perceptions on Student Achievement in TIMSS Mathematics: A Comparison of Two Countries. International Journal of Testing, 61-77. https://doi.org/10.1080/15305058.2011.621568

Grønmo, L., Pavešić, B., Nyström, P., \& Onstad, T. (2013). The Significance of TIMSS and TIMSS Advanced Mathematics Education in Norway, Slovenia and Sweden.

IEA. (2015). TIMSS 2015 Key factors at school. Retrieved October 27, 2017, from https://newsroom.didactiefonline.nl/uploads/PDF/161128-IEA-infographics-vd-ENG-v05.pdf

Kilpatrick, J. (2003). What works? In S. L. Senk, \& D. R. Thompson (Eds.), Standards-based school mathematics curricula: What are they? What do students learn? (pp. 471-493). Mahwah, NJ: Erl-baum. 
https://doi.org/10.4324/9781003064275-20

Kim, S., Park, J., Park, S., \& Kim. Y. (2013). The Effects of School and Students'Educational Contexts in Korea, Singapore, and Finland Using Timss 2011.

Lessani, A., Yunus, A., Tarmiz, R., \& Mahmud, R. (2014). Why Singaporean 8th Grade Students Gain Highest Mathematics Ranking in TIMSS (1999-2011). International Education Studies, 7, 173-181. https://doi.org/10.5539/ies.v7n11p173

Mizell, H., (2010). Why professional development matters. Learning Forward.

Mullis, I., Martin, M., Hooper, M., \& Foy, P. (2016). TIMSS 2015 International Results in Mathematics Grade 4. TIMSS \& PIRLS International Study Center, Boston College.

National Council of Teachers of Mathematics. (2000). Curriculum and evaluation standards for school mathematics. Reston, VA: NCTM.

Provasnik, S., Malley, L., Stephens, M., Landeros, K., Perkins, R., \& Tang, J. H. (2016). Highlights From TIMSS and TIMSS Advanced 2015: Mathematics and Science Achievement of U.S. Students in Grades 4 and 8 and in Advanced Courses at the End of High School in an International Context (NCES 2017-002). U.S. Department of Education, National Center for Education Statistics. Washington, DC.

Reys, R. E., Tarr, J. E., \& Chávez, O. (2004, April). Do textbooks matter? Findings from a study of NSF and non-NSF mathematics curriculum materials. Paper presented at the National Council of Supervisors of Mathematics Annual Conference, Philadelphia, PA.

Ritzen, J. (2013). International Large-Scale Assessments as Change Agents. In M. von Davier et al. (Eds.), The Role of International Large-Scale Assessments: Perspectives from Technology, Economy, and Educational Research (pp. 13-24). https://doi.org/10.1007/978-94-007-4629-9_2

Rutkowski, E., \& Prusinski, D. (2011). The Limits and Possibilities of International Large-Scale Assessments. Center for Evaluation \& Education Policy, 9(2).

Rutkowski, L., Gonzalez, E., Joncas, M., \& Davier, M. (2010). International Large-Scale Assessment Data: Issues in Secondary Analysis and Reporting. Research News and Comment, 39(2), 142-151. https://doi.org/10.3102/0013189X10363170

Senk, S. L., \& Thompson, D. R. (Eds.). (2003). Standards-based school mathematics curricula: What are they? What do students learn? Mahwah, NJ: Erlbaum.

Smeed, J. (2009). Controlled rapid approach to curriculum change: Addressing the needs of test-based accountability in schools (PhD Thesis, Queensland University of Technology, Brisbane).

Stein, M. K., \& Smith, M. S. (2010). The influence of curriculum on student learning. In B. Reys, \& B. Reys (Eds.), K-12 mathematics curriculum: Issues, trends, and future directions (pp. 351-362). Reston, VA: National Council of Teachers of Mathematics.

Stenhouse, L. (1984). Evaluating curriculum evaluation. In C. Adelman (Ed.), The politics and ethics of evaluation (pp. 77-86). London: Croom Helm.

Tanner, D., \& Tanner, L. (2007). Curriculum Development: Theory into Practice (4th ed.). Upper Saddle River, New Jersey Columbus, Ohio: Pearson Merrill Prentice Hall.

U.S. Department of Education. (n.d.). What the Third International Mathematics and Science Study (TIMSS) Means for Systemic School Improvement. National Institute on Educational Governance, Finance, Policymaking, and Management.

Wang, Y., Bian, Y., Xin, T., Kher, N., Houang, R., \& Schmidt, H. (2012). Examination of Mathematics Intended Curriculum in China From an International Perspective. US-China Education Review, 150-162.

Woodward, J. (2004). Mathematics education in the United States: Past to present. Journal of Learning Disabilities, 37(1), 16-31. https://doi.org/10.1177/00222194040370010301

\section{Copyrights}

Copyright for this article is retained by the author(s), with first publication rights granted to the journal.

This is an open-access article distributed under the terms and conditions of the Creative Commons Attribution license (http://creativecommons.org/licenses/by/4.0/). 